\title{
El obispo Diego Ramírez de Villaescusa y su relación con el arte flamenco
}

\author{
Bishop Diego Ramírez de Villaescusa and his Relationship \\ with Flemish Art
}

\section{Alejandro Sáez Olivares ${ }^{1}$}

Universidad Rey Juan Carlos

\begin{abstract}
Resumen: En el presente trabajo se analiza la figura del obispo Diego Ramírez de Villaescusa y su papel como consumidor y comitente de obras de arte flamencas. Estamos ante un personaje integrado en los círculos de poder políticos, cercano a las últimas tendencias humanísticas y culturales, cuya carrera profesional le permitió acercarse a los principales focos artísticos de su tiempo.

Como capellán mayor de la capilla de Juana, tuvo la oportunidad de acompañarla en su periplo flamenco, accediendo así al lujo y sofisticación de la Corte de Felipe el Hermoso. Comprobaremos cómo, aprovechando los contactos que su posición le facilitaba, adquirió algunas piezas de gran calidad, como el libro de horas de Leonor de la Vega, el tapiz de la Crucifixión o tablas devocionales, utilizándolas como presentes para agasajar a distintas personalidades. No obstante, también adquiriría obras para sí mismo, ya fueran libros o tapices, demostrando interés por el arte que se practicaba en territorio brabanzón. Asimismo, analizaremos las obras artísticas documentadas y su relevancia para la comprensión de Villaescusa como patrono de las artes.
\end{abstract}

Palabras clave: Arte flamenco; mecenazgo; libro de horas; tapicería; pintura.

Abstract: This paper discusses the figure of Bishop Diego Ramírez de Villaescusa and his role as a consumer and principal of Flemish works of art. We are faced with a character integrated into the circles of political power, close to the last humanistic and cultural tendencies, whose professional career allowed him to approach the main artistic focuses of his time.

1 (1) http://orcid.org/0000-0003-3600-9/22

(C) 2021 Philostrato. Revista de Historia y Arte 
As the main chaplain of the chapel of Juana, he had the opportunity to accompany her on her Flemish journey, thus accessing the luxury and sophistication of the Court of Philip the Beautiful. We will see how, taking advantage of the contacts that his position provided him, he acquired some high-quality pieces, like the book of hours of Leonor de la Vega, the Crucifixion tapestry, or devotional panels, using them as present to caress different personalities. However, he would also acquire works for himself, demonstrating an interest in the art that was practiced in Brabant territory. We will also analyze the documented artistic works and their relevance to Villaescusa's understanding as patron of the arts.

Keywords: Flemish art; patronage; book of hours; tapestry; painting.

\section{El prelado}

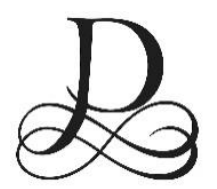

iego Ramírez de Villaescusa (1459-1537) fue un obispo cortesano que desempeñó diversas funciones al servicio de los Reyes Católicos, de Juana I de Castilla, e incluso de Carlos V. Su carrera profesional estuvo condicionada, desde un principio, por las relaciones de poder en el entorno de las distintas casas reales con las que tuvo contacto, las cuales guiaron, en gran parte, su carrera eclesiástica.

Tras estudiar e impartir clases de Retórica y Teología en el Colegio de San Bartolomé de Salamanca, terminó por acceder a diversas personalidades de la corte, las cuales le proporcionaron sus primeras prebendas ${ }^{2}$. Disfrutó de una brillante carrera profesional, protegido por fray Hernando de Talavera y Luis Osorio, quien le llevaría con él a Flandes como capellán mayor de la archiduquesa Juana ${ }^{3}$. Su dedicación al servicio de los monarcas hizo que fuera recompensado ampliamente con la concesión diversos cargos, como el obispado de Málaga. Entre 1511 y 1515 sirvió al rey Fernando visitando instituciones de patronato regio y presidiendo la Audiencia de Valladolid, consiguiendo finalmente una nueva promoción episcopal con la llegada de Carlos V, cuando fue nombrado obispo de Cuenca ${ }^{4}$. Tras el conflicto de las Comunidades fue señalado por los vencedores, teniendo que exiliarse a Roma bajo la protección de Adriano VI. La prematura muerte del pontífice y el Ilamamiento para que retornase a su diócesis hicieron que volviera a Cuenca a principios de 1524 retomando sus labores pastorales, las cuales compaginó con encargos que llegaban desde el entorno del emperador, hasta que le alcanzó la muerte en 1537.

\footnotetext{
2 Gil González Dávila, Historia de las Antigüedades de la ciudad de Salamanca, (Salamanca, 1606). Publicado por Baltasar Cuart Moner en Salamanca, (Salamanca: Ediciones Universidad de Salamanca, 1994), p. 430.

3 Villaescusa fue uno de los pocos miembros castellanos de la casa de Juana que permanecieron tras la reordenación que de la misma llevó a cabo el archiduque Felipe. Félix Labrador Arroyo, "La evolución y el papel de las casas reales en Castilla entre 1504 y 1516", en Poder, sociedad, religión y tolerancia en el mundo hispánico, de Fernando el Católico al siglo XVIII, eds. Eliseo Serrano Martín, Jesús Gascón Pérez, (Zaragoza: Institución Fernando el Católico, Excma. Diputación de Zaragoza, 2018), pp. 119-155.

${ }^{4}$ Mateo López, Memorias históricas de Cuenca y su obispado, (Cuenca: Instituto Jerónimo Zurita del Consejo Superior de Investigaciones Científicas, 1949-1953), pp. 235, 236.
} 
El suceso que marcó, sin ningún tipo de duda, la carrera de nuestro personaje fue su viaje a Flandes junto a Juana. Este hecho supuso un ascenso en cuanto a sus responsabilidades dentro de la Casa de la archiduquesa y también un trampolín hacia las más importantes dignidades. Según las fuentes que hemos manejado, Villaescusa se integró activamente en la vida cortesana flamenca. Es de suponer que su constante presencia en el entorno de Juana le llevaría a contemplar fastuosas costumbres y tradiciones, llegando a aceptar y adoptar los lujosos modelos foráneos, los cuales aplicaría según sus necesidades. Se relacionó con personas letradas de la Corte de los archiduques, sobre todo a su paso por Lovaina en 1498, cuando debió entrar en contacto con Adriano de Utrecht. Asimismo, debió establecer relaciones con algunos de los personajes más influyentes ${ }^{5}$, pues cuando años después envió a su sobrino Pedro Ramírez a la Corte del rey Carlos, le recomendó que trabara amistad con eminentes felipistas como eran Guillermo de Croy, monseñor de Chievres, François de Melun o el mismo Diego de Guevara 6 .

Villaescusa y Adriano de Utrecht fueron dos personajes cuyas trayectorias corrieron paralelas a la política y religión de su tiempo. Entroncan con el modelo de obispos cortesanos, empleados durante la mayoría de su tiempo en servir dentro de la Corte y reconocidas eminencias en materia de teología. Dando veracidad al testimonio que situó a Villaescusa en Lovaina, donde se graduó como maestro en Teología7, podemos situar el primer encuentro entre ambos durante el año 1498. De ser así, habría pasado las pruebas de maestría ante los principales conocedores de la materia, por lo que resulta inevitable que entre ellos, estuviera el principal teólogo de la Universidad. De este modo, encontraríamos un signo de reconocimiento hacia Villaescusa, lo que podría haber facilitado que cuando se volvieran a encontrar en Castilla, Adriano le concediera sus favores ${ }^{8}$.

Sobre su relación con Guillermo de Croy, monsieur de Chievres, se resume en algunas recomendaciones a su sobrino para que se acercase a él ${ }^{9}$, pero nuestro personaje no lo haría si no estuviera seguro de que sería bien recibido. El mismo tratamiento encontramos con respecto a Diego de

\footnotetext{
${ }^{5}$ Para un acercamiento bibliográfico a la actualidad hispanoflamenca en torno al 1500, véase, al respecto, Raymond Fagel, "Juana de Castilla y los Países Bajos: la Historiografía neerlandesa sobre la reina", en Juana I de Castilla, 1504-1555: de su reclusión de Tordesillas al olvido de la historia: I Simposio Internacional sobre la Reina Juana I de Castilla, coord. Miguel Ángel Zalama Rodríguez, (Tordesillas [Valladolid]: Ayuntamiento de Tordesillas, 2006), pp. 87-706.

${ }^{6}$ Félix G. Olmedo, Diego Ramírez Villaescusa (1459-1537), fundador del Colegio de Cuenca y autor de los cuatro diálogos sobre la muerte del Príncipe Don Juan, (Madrid: Editora Nacional, 1944), pp. 109 y ss. Los Guevara establecieron en Flandes una interesante red de patrocinio y coleccionismo de obras artísticas, siendo tremendamente valorado su gusto, ya en su tiempo; Elena Vázquez Dueñas, Felipe de Guevara. Comentario de la pintura y pintores antiguos, (Madrid: Akal, 2016), pp. 29-43.

7 Olmedo, Diego Ramírez de Villaescusa, p. 65.

8 Se observa entre ambos un tipo de relación de patronazgo en la que ambos personajes salieron beneficiados de los servicios que se prestaron mutuamente. Adriano contó en Castilla con un apoyo fiel y leal a la Corona, que llevó a cabo para él misiones de protección y mediación, dirigidas en todo momento para lograr sus objetivos de gobierno en un momento especialmente delicado. Villaescusa, por su parte, fue beneficiado primeramente a través de la protección que el flamenco le brindó ante Carlos $V$ y posteriormente, con la concesión de mercedes y bulas que le facilitaron la erección institucional del Colegio Mayor de Cuenca. Alejandro Sáez Olivares, El obispo Diego Ramírez de Villaescusa y su papel como mecenas de las artes, tesis doctoral, Universidad Rey Juan Carlos (Madrid: 2020), pp. 304-311.

9 "... a mi ver de los de allá deveys tomar familiaridad con el chanceller y mossior de chievre y el obispo de coria". Olmedo, Diego Ramírez de Villaescusa, p. 121.
} 
Guevara, el cual pertenecía a una familia de larga tradición en el servicio en la corte borgoñona ${ }^{10}$. Sin embargo, sí parece traslucir cierta amistad de Villaescusa con François de Melun conde de Espinoy, quien había sido nombrado recientemente miembro de la orden del Toisón de Oro y consejero flamenco, en palabras del conquense: "... que es muncho mi señor y amigo"11.

Ramírez de Villaescusa ha pasado a la posteridad como un gran protector de la cultura y las letras. Impulsado por su contacto con las élites de poder, trató de integrarse en ellas a través de su promoción artística y cultural, protegiendo a literatos, impulsando capillas musicales, coleccionando lujosas piezas de orfebrería y atesorando tapices. Asimismo, promovió gran cantidad de obras, tanto en el ámbito episcopal como en el personal, levantando fastuosas edificaciones y adornándolas con valiosas obras. Así, encontramos, entre los episcopales, proyectos tan ambiciosos como la portada del Sagrario, en Málaga, la iglesia colegial de Antequera o la sala capitular de la catedral de Cuenca. Por otra parte, sus proyectos personales le llevaron a erigir una fastuosa capilla y un grandioso palacio en su villa natal, sin olvidar su gran proyecto vital: el Colegio Mayor de Cuenca, en Salamanca ${ }^{12}$. Veamos pues, cómo desarrolló esta actividad cultural durante el tiempo que residió en la Corte de los archiduques.

\section{El contexto artístico}

Mientras que en la Italia del Quattrocento había triunfado el Renacimiento que estudiaba las anatomías, las reglas matemáticas y las antigüedades romanas, el Norte de Europa se había mantenido fiel a las tradiciones góticas ${ }^{13}$. Sin embargo, sus manifestaciones artísticas habían experimentado un impulso sin parangón a lo largo del siglo XV. El establecimiento de los grandes duques de Borgoña en las ciudades del Norte provocó el desarrollo y consumo de manufacturas cada vez más suntuosas, inspiradas por el preciosismo francés, imponiendo un lujo cortesano que marcaría la moda de las principales cortes europeas. Este gusto por el boato se llevaba al extremo en las diferentes cortes europeas, en las que resultaba inseparable de las distintas manifestaciones artísticas ${ }^{14}$. Arquitectónicamente se extendió un gusto internacional por el gótico flamígero, instalándose y desarrollándose durante el siglo XV en aquellos territorios que gozaban de un relativo tiempo de paz y prosperidad, como eran Borgoña y Flandes ${ }^{15}$. Derivado de la intensa

\footnotetext{
${ }^{10}$ Vázquez, Felipe de Guevara, pp. 31, 32. Su ascendencia sobre las decisiones de Felipe, su papel como enlace entre flamencos y castellanos, así como su alto nivel cultural, hacen de su posible relación con Villaescusa una de las más interesantes a investigar.

11 Olmedo, Diego Ramírez de Villaescusa, pp. 116, 117.

12 Se ha analizado su papel en la promoción de las artes, así como su gusto artístico, en Sáez, Obispo Diego Ramírez de Villaescusa.

${ }^{13}$ Ernst H. Gombrich, Historia del Arte, (Madrid: Alianza Forma, 15a edición, 1992), p. 204.

${ }_{14}$ M. Ángel Zalama Rodríguez, "Primacía de los tapices entre las artes figurativas en España entre los siglos XV y XVI" en Los triunfos de Aracne. Tapices flamencos de los Austrias en el Renacimiento, eds. Fernando Checa Cremades y Bernardo J. García García, (Madrid: Fundación Carlos de Amberes, 2011), p. 20.

${ }_{15}$ José Fernando González Romero, El gótico alemán en España y la dinastía de los Colonia. La cristalización de las torres caladas: Friburgo, Burgos y Oviedo, (Gijón: Ediciones Trea, 2016), p. 13.
} 
actividad municipal, comercial y gremial que se daba en aquellas ciudades, la "verdadera gloria de esta escuela" la constituyen las construcciones de carácter civil como las lonjas, las casas gremiales o los ayuntamientos ${ }^{16}$.

Las artes visuales se inscribían en el contexto de la burguesía urbana como clase dominante, asociada además a los duques de Borgoña, por lo que se trataba de una clientela que exigía un arte sofisticado, suntuoso y atractivo visualmente. Un arte de la ostentación que definía la riqueza profesional llenaba el interior de sus casas y les vestía en los actos públicos. Las obras destacaban por su perfección técnica y una ejecución virtuosa, tan superior a las obras producidas en otros países, que suscitaron el interés de los comitentes en proveerse de productos flamencos. Este interés se acentuaba en los reinos hispánicos si tenemos en cuenta la espiritualidad dominante de los Países Bajos, la devotio moderna, un tipo de religiosidad emocional que encontraba paralelismos con la tradición devocional peninsular ${ }^{17}$. Esta tradición estaba impregnada de un sentimiento, según el cual, el hombre pretendía volver a su estado previo al pecado original a través la imitación de Cristo. Se rechazaba la exhibición de las emociones religiosas, manteniéndolas en el interior, invitando al devoto a acercarse a la meditación y la oración a través de la lectura de los textos de los Padres de la Iglesia, de las vidas de santos, eremitas, etc. ${ }^{18}$.

Las referidas características se hacían extensibles a todos los niveles de creación artística: desde la pintura, a la tapicería, pasando por la platería o la música ${ }^{19}$. Con el cambio de siglo, los flamencos miraban a su pasado en busca de la excelencia y la gloria, lo que pictórica y formalmente se tradujo en una recuperación de los modelos de Jan van Eyck, el maestro de Flémalle y de Roger van der Weyden. Sin embargo, algunos artistas como Gerard David supieron volver a los fundadores de la tradición nórdica implementando una renovación que incluía novedades italianizantes a nivel compositivo, atmosférico y cromático ${ }^{20}$.

Con el tiempo, se fue desarrollando una industria en torno a la producción de obras artísticas propias de Flandes o Brabante en grandes cantidades, como los retablos devocionales, la pintura sobre tabla, los tapices o los libros de horas. Estas obras se exportaban a otros países, propagando las características y el estilo del arte flamenco por todas las cortes europeas ${ }^{21}$.

\footnotetext{
16 Diego Angulo Íñiguez, Historia del Arte, Tomo I, (Madrid: Raycar, 1980), p. 438. En este contexto, se ha apuntado hacia la posibilidad de que esta arquitectura, plena de ornamentos y riqueza decorativa, surgiera al mismo tiempo en Flandes y Castilla, donde encontramos fundamentos estilísticos comunes. Krista de Jonge, "Flandes y Castilla. La arquitectura en la época de los Reyes Católicos" en El arte en la Corte de los Reyes Católicos. Rutas artísticas a principios de la Edad Moderna, eds. Fernando Checa Cremades y Bernardo J. García García, (Madrid: Fundación Carlos de Amberes, 2005), p. 177.

17 Joaquín Yarza Luaces, Los Reyes Católicos. Paisaje artístico de una monarquía, (Madrid: Editorial Nerea, 1993), p. 378.

18 Mathilde van Dijk, "The Devotio Moderna, the Emotions and the Search for 'Dutchness'", Low Countries Historical Review, 129-2, (2014), pp. 20-41.

${ }^{19}$ Existe una amplia bibliografía al respecto, destacando el trabajo de Tess Knighton, Companion to Music in the Age of the Catholic Monarchs, (Leiden: Brill, 2017).

${ }^{20}$ Erwin Panofsky, Los primitivos flamencos, (Madrid: Cátedra, 1998, 2a edición, 2016), pp. 344-345.

21 Joaquín Yarza Luaces, "El arte de los países bajos en la España de los Reyes Católicos" en Reyes y mecenas. Los Reyes Católicos, Maximiliano I y los inicios de la Casa de Austria en España, coord. Fernando Checa, (Madrid: Electa, 1992), pp. 134-135.
} 
Gracias a esta difusión, los comitentes reclamarían a los artistas locales que imprimiesen ese estilo en las obras que les encargaban. Estos acudían a las estampas y reproducciones para inspirarse y copiaban estilos y composiciones, en algunos casos de manera demasiado evidente. Aquellos que contaban con posibles, contrataban directamente a artistas nórdicos, que buscaban en las casas reales y nobiliarias su modo de subsistencia.

La recepción de estas corrientes en Castilla se hizo patente desde los textos de viajeros y cronistas castellanos en los que se ensalzaba la excelencia y lujo de la propia Corte de Borgoña, señalada como un referente europeo y proponiéndola como modelo a seguir ${ }^{22}$. Sin embargo, el arte considerado como de influencia flamenca en las ciudades castellanas, se debía más a una combinación de elementos de procedencia diversa, de entre los cuales los artistas seleccionaban los que consideraban más convenientes para su objetivo artístico. Estos elementos sufrían un proceso de relectura y adaptación durante su recepción, del mismo modo que había ocurrido con otros movimientos artísticos como el gótico francés en otras cortes europeas, o el renacimiento italiano en países como Polonia, Hungría y Bohemia ${ }^{23}$.

Este contexto artístico era bien conocido y mejor apreciado en la Castilla de finales del siglo $X V$, por lo que resultaba habitual que, quienes se desplazaban a Bruselas, Brujas o Amberes, contactaran con talleres locales para hacerse con alguna obra a la moda flamenca. Villaescusa tuvo además la fortuna de poder desplazarse junto a Juana a través de toda la geografía de los Países Bajos, conociendo de primera mano las tendencias y artistas dominantes en cada disciplina. Esta posición privilegiada se tradujo en la adquisición de obras de arte como fórmula de obsequio y en un profundo conocimiento de las novedades artísticas que impregnaría las obras que patrocinó durante los siguientes lustros.

A continuación, veremos algunas de las obras que Villaescusa adquiriría durante su estancia en Flandes y que han quedado debidamente documentadas.

\section{Libro de horas de Leonor de la Vega}

Los libros de horas son libros de devoción que surgieron alrededor del s. XIV fruto de la combinación del Breviario con sus apéndices y el Salterio. El enriquecimiento de los oficios divinos llevó a añadir los distintos elementos

\footnotetext{
22 Las referencias a intelectuales como Diego de Valera o Alonso de Palencia se citan en David Nogales Rincón, "Sobre la cultura "borgoñona" y su recepción en Castilla en el siglo XV", en La Casa de Borgoña. La Casa del rey de España, eds. José Eloy Hortal Muñoz y Félix Labrador Arroyo, (Leuven: Leuven University Press, 2014), pp. 23-35; Con respecto a la recepción de la pintura flamenca en Castilla: María Pilar Silva Maroto, "La pintura hispanoflamenca en Castilla" en La pintura gótica hispanoflamenca: Bartolomé Bermejo y su época, ed. Francesc Ruiz Quesada, (Barcelona: Museu Nacional d'Art de Catalunya, Museo de Bellas Artes de Bilbao, 2003), pp. 77-86.

${ }^{23}$ Ibídem, pp. 28-29.
} 


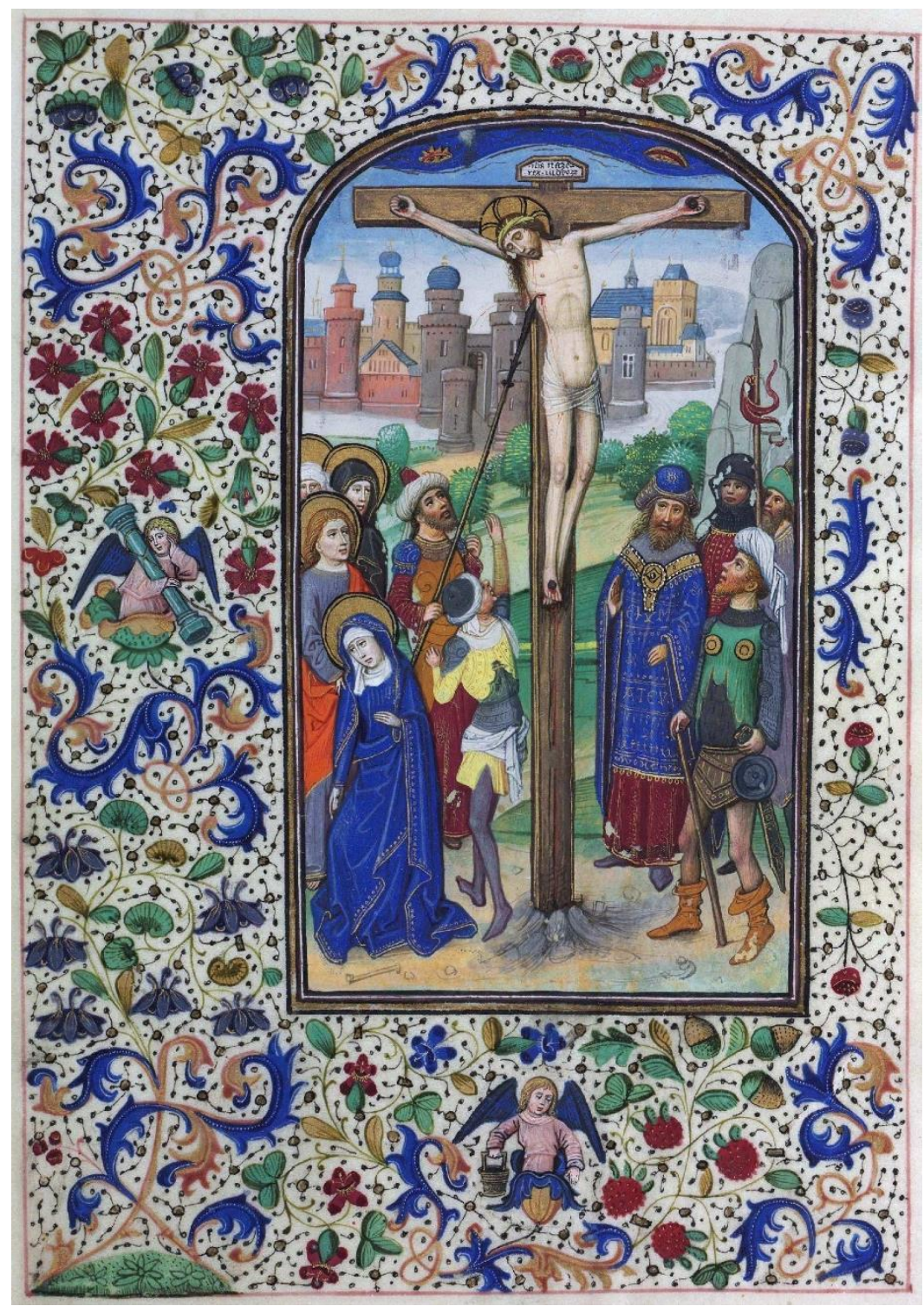

Fig. 1. Willem Vrelant, Crucifixión. Libro de Horas de Leonor de la Vega. Siglo XV. Madrid @ Biblioteca Nacional (Vitr/24/2).

que terminaría por configurarlos a finales de la Edad Media ${ }^{24}$, incorporando las letanías de los santos, el oficio de difuntos y el oficio de la Virgen ${ }^{25}$. Hacia el siglo XV estos manuscritos se popularizaron entre las élites municipales, que buscaban poseer objetos que marcasen un alto rango social, pasando a ser considerados productos artísticos de primer nivel y objeto de coleccionismo.

24 Dejamos referencia de algunos estudios imprescindibles para aproximarse a la temática, como por ejemplo los clásicos: Victor Leroquais, Les libres d'heures manuscrits de la Bibliothèque Nationale, (París: Maçon Protat frères, 1927), 3 vols.; Leon M. J. Delaissé, "The importance of Books of Hours for the History of the Medieval Book", en Gatherings in honor of Dorothy E. Miner, eds. Dorothy Eugenia Miner, Ursula E. McCracken, Lilian M. C. Randall, Richard H. Randall, (Baltimore: Walters Art Gallery, 1974), pp. 203-225; Roger S. Wieck, Painted prayers: the book of hours in medieval and Renaissance art, (New York: George Braziller, in association with the Pierpont Morgan Library, 1997).

${ }^{25}$ Ana Domínguez Rodríguez, "Libros de Horas en la Corona de Castilla. Hacia un estado de la cuestión", Anales de Historia del Arte, 10, (2000), pp. 9-54. 
La disposición de los distintos elementos nunca ha sido fijada, por lo que no es habitual que haya dos libros exactamente iguales, siendo el calendario el único punto en común, que variará según la diócesis para la que sea encargado. Litúrgicamente se caracterizaban por una gran libertad textual, donde los copistas disponían su composición a su albedrío, añadiendo oraciones a su gusto e, incluso, algunos temas profanos ${ }^{26}$.

Durante el siglo XV, y debido al aumento de la demanda de estas obras de arte, surgieron talleres especializados en su elaboración para encargos personales. Estos talleres eran dirigidos por un maestro que marcaba las pautas generales y le daba el toque de calidad a la obra, apoyado por varios aprendices que realizan las labores secundarias. La decoración se compone de iniciales decoradas o historiadas, que desarrollan orlas que llenan los espacios, además de las escenas miniadas que ocupan el folio por entero. Si bien en un principio, se impone el gusto de tradición nórdica, se adaptará a las nuevas corrientes estéticas renacentistas, incorporando hojas de acanto, candelieri, putti, etc.

Para añadir más valor a la obra, se incluía en las miniaturas algún motivo dorado, tal y como se practicaba en las tablas góticas, y esa incorporación del oro a la obra provocaba que su coste aumentara considerablemente. La encuadernación también era objeto de decoración que otorgaba cierto empaque al libro. Se protegía introduciéndolo en un estuche que se cosía a una cubierta llamada camisa, que hacía más sencillo su transporte y manejabilidad ${ }^{27}$.

El libro de horas de Leonor de la Vega se conserva en la Biblioteca Nacional de Madrid (Vtr. 24.2) y contiene 203 folios de distinta calidad. En ellos encontramos 23 miniaturas a página completa (Fig. 1), enmarcadas por un rectángulo dorado que se curva en su parte superior. Alrededor del mismo se rellena el espacio con motivos vegetales y frutas de distintos colores, así como de un punteado dorado y algunas efigies de animales fantásticos. En otras páginas encontramos hasta 33 letras iniciales historiadas, decoradas en su interior y rodeadas a su vez por orlas similares a las anteriormente descritas (Fig. 2) 28 .

Respecto a la historia del libro, en el primer folio se puede leer una inscripción que nos aclara que el manuscrito fue enviado por Diego Ramírez de Villaescusa desde Flandes a D. García Laso de la Vega, embajador español en Roma: "Hic liber dabit a Rome magnifico domino garcie lasso serenissimonum regis \& reginae hispaniarum oratori. Mittit a ex bruxellis a

\footnotetext{
${ }^{26}$ Ibídem, p. 18.

27 Juana Hidalgo Ogáyar, Libro de Horas de Leonor de la Vega, (Madrid: Versol, 2000), estudio introductorio que forma parte de la edición facsímil del Libro de Horas de Leonor de la Vega de la Biblioteca Nacional. ${ }^{28} \mathrm{Hemos}$ podido consultar el ejemplar a través de la Biblioteca Digital Hispánica, en la página web de la Biblioteca Nacional de Madrid: (En web: http://bdh.bne.es/bnesearch/biblioteca/Libro\%20de\%20horas\%20de\%20Leonor\%20de\%20la\%20Vega \%20\%20\%20/als/bdh0000048889;jsessionid =45FE343805BC746B7EAB35923A1B9208 consultada: 15 de mayo de 2019).
} 


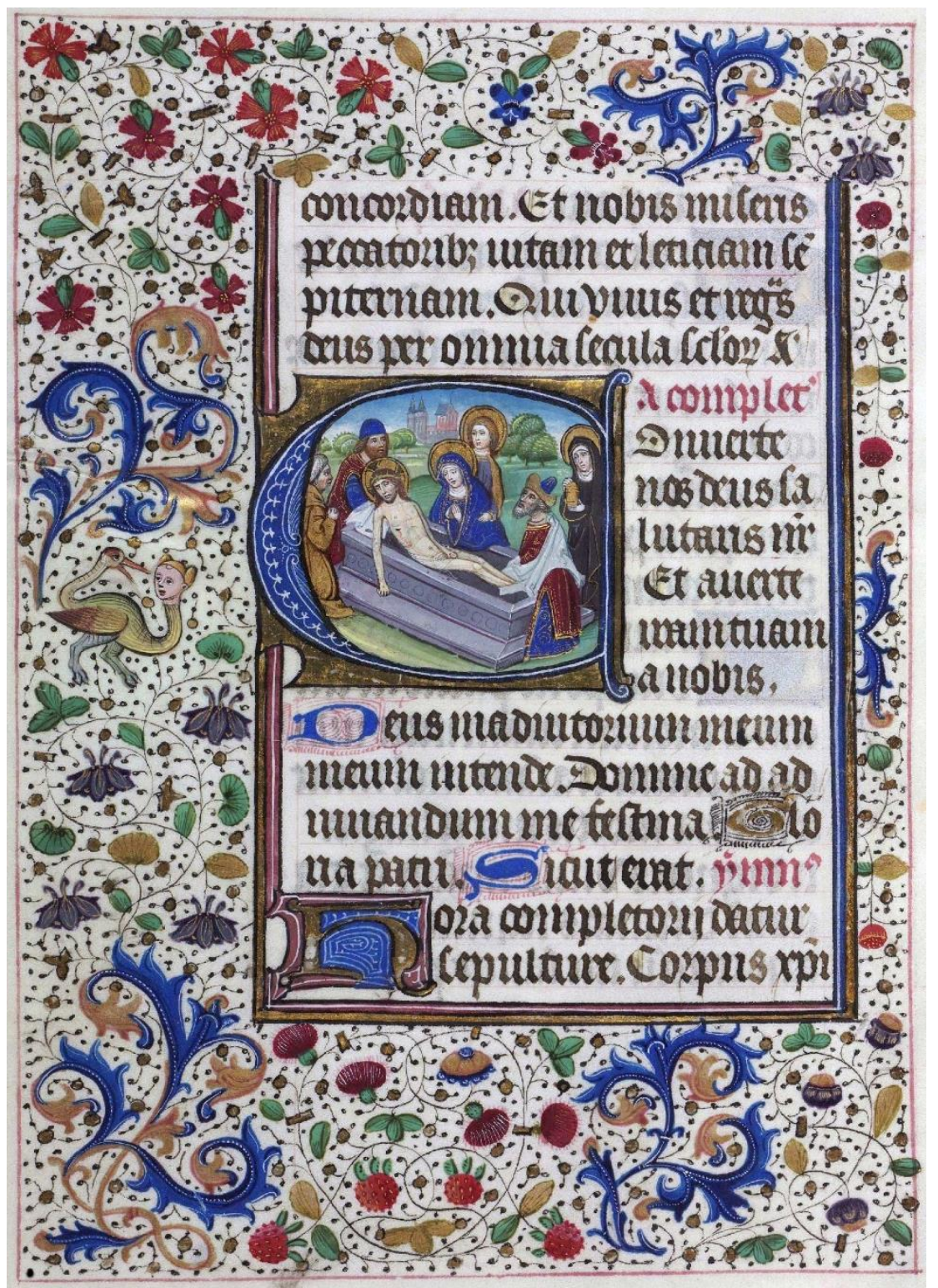

Fig. 2. Willem Vrelant, Detalle letra inicial. Libro de Horas de Leonor de la Vega. Siglo XV. Madrid (C Biblioteca Nacional (Vitr/24/2).

primo Capellano illustrissime ioane austriae archiducisse electo astoricense" (Fig. 3) $)^{29}$.

También se puede leer que pertenecía a Doña Leonor de la Vega, hija del embajador, y un poco más adelante tenemos una inscripción en la que un inquisidor da el visto bueno a la obra en 1574. Estos son los datos que nos aporta una primera inspección del libro, donde no consta artífice ni taller ejecutor, sin fechas determinadas y sin marcas heráldicas que nos indiquen para quién fue encargada su manufactura. Ahora bien, durante las últimas décadas del siglo XX, varios investigadores han intentado arrojar luz sobre la

29 "Este libro dado en Roma al magnífico señor García Lasso, orador de los serenísimos rey y reina de España. Enviado desde Bruselas por el primer Capellán de la ilustrísima Juana archiduquesa de Austria electo asturicense". 


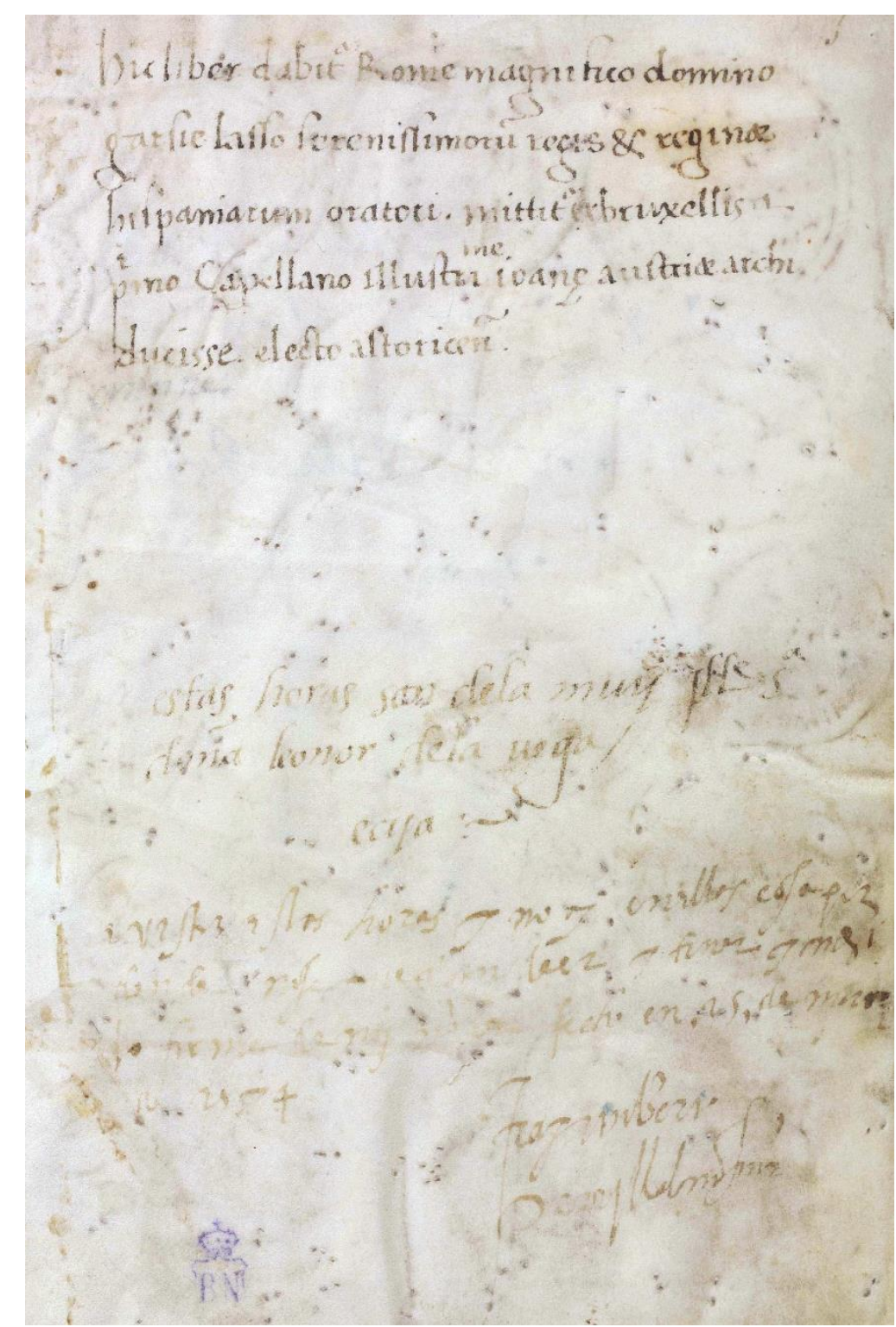

Fig. 3. Willem Vrelant, Inscripción. Libro de Horas de Leonor de la Vega. Siglo XV. Madrid @ Biblioteca Nacional (Vitr/24/2).

autoría y procedencia del manuscrito. Ha sido desde los estudios de Durrieu cuando se ha venido atribuyendo al miniaturista holandés Guillermo Vrelant -también conocido como Weylant o Vreeland ${ }^{30}$, más por similitudes estilísticas que por datos fehacientes. Bernard Bousmanne sigue en la misma línea afirmando que salió de la mano de Vrelant y que lo podemos comparar tanto en cuanto a su estilo como en cuanto a su riqueza iconográfica con Las Horas de Aremberg del Museo Getty, e incluso con el Libro de Horas de Isabel la Católica ${ }^{31}$. Ana Domínguez Rodríguez no se desmarca tampoco de las teorías

\footnotetext{
30 Paul Durrieu, "Manuscrits d'Espagne remarquables par leur peinture et par la beauté de leur exécution", Bibliothèque de I'Ecole de Chartres, 54, (1983).

${ }^{31}$ Bernard Bousmanne, "Item à Guillaume Wyelant aussi enluminieur", en Willem Vrelant. Un aspect de l'enluminure dans les Pays-Bas méridionaux sous le mécénat de ducs de Bourgogne Philippe le Bon el Charles le Témeráire, (Bruxelles: Bibliothèque Royal de Belgique, 1997), p. 183.
} 
de Durrieu y en su opinión el manuscrito "Es de bastante calidad"32. Asimismo, se refiere a las orlas y dibujos fantasiosos como típicos de Vrelant, así como alguna de las composiciones más representativas, como es la temática de la Anunciación.

Por nuestra parte, la comparación estilística del ejemplar con el Libro de Horas de la Reina Doña Leonor nos acerca aún más al taller de Vrelant. Se trata de una obra datada en $1470^{33}$, de excelente calidad, realizada en grisalla y oro, con detalles en azul, donde las decoraciones marginales y las escenas principales se asemejan a las del libro adquirido por Villaescusa.

Las noticias que tenemos de este artista holandés nacido en Utrecht son que, a partir de 1454 figura en los registros de la gilda de miniaturistas de San Juan Evangelista de Brujas, aunque no aparece como maestro iluminador hasta $1470-71^{34}$. Existe gran cantidad de datos de sus encargos, tanto como miniaturista como en el papel de patrocinador, hasta su fallecimiento en $1481^{35}$. Su estilo se caracteriza por un cuidado dibujo, figuras inexpresivas, escaso interés en los efectos de la luz y paisajes esquemáticos, con reminiscencias de los iluminadores parisinos del primer cuarto del siglo $\mathrm{XV}^{36}$. Durante su vida activa se conocen importantes encargos para el duque de Borgoña Felipe el Bueno, así como los nombres de algunos de sus ayudantes, hecho este último que ha dado pie a algunos estudiosos del tema a pensar que tuvo su propio taller, caso de Delaissé37. Este hecho podría tener importancia en cuanto al establecimiento de una escuela que practicase y difundiese sus preceptos estilísticos más allá de su muerte. Este podría ser el caso de nuestro libro de horas, que fue enviado a Roma casi con total seguridad entre diciembre de 1498 y los primeros meses de 1499. Tomamos la referencia de estas fechas, pues Diego Ramírez fue nombrado obispo de Astorga en noviembre de 1498 y está documentado en Bruselas el día dieciséis del mismo mes asistiendo a felicitar a los archiduques por el nacimiento de la infanta Leonor. Don García Laso de la Vega, por su parte, fue cesado de su cargo como embajador en Roma en 1498, aunque permaneció allí unos meses más apoyando a los nuevos embajadores ${ }^{38}$.

Cuando adquirió el manuscrito nuestro obispo es todavía una incógnita, pues no parece un encargo personal, ya que no figura ningún escudo ni insignia que así lo identifique. No debemos olvidar que hasta 1510 no recibiría

\footnotetext{
32 Ana Domínguez Rodríguez, Libros de Horas del siglo XV en la Biblioteca Nacional, (Madrid: Fundación Universitaria Española, 1979).

33 Se conserva en BNL. Ms. Cód. 165.

${ }^{34}$ Los primeros documentos en los que figura como ciudadano de Utrecht se remontan a 1449. En los años 60 se conocen dos aprendices femeninas y en los 70 otros dos varones, que podrían ser sus hijos. Iluminating the Renaissance: The Triumph of Flemish Manuscript Painting in Europe, ed. Thomas Kren y Scot McKendrick, (Los Ángeles: Paul Getty Museum; Londres: Royal Academy of Arts, 2003), p. 117.

${ }^{35}$ Se han documentado más de setenta manuscritos asociados a su mano, ya fueran realizados en su totalidad o en parte, conformando uno de los talleres más prolíficos del momento. Ibídem.

${ }^{36}$ Ibídem.

37 Delaissé, "The importance of Books of Hours", pp. 203-225.

38 Miguel Ángel Ochoa Brun, Historia de la diplomacia española, vol. IV, (Madrid: Ministerio de Asuntos Exteriores, 1995), p. 131.
} 


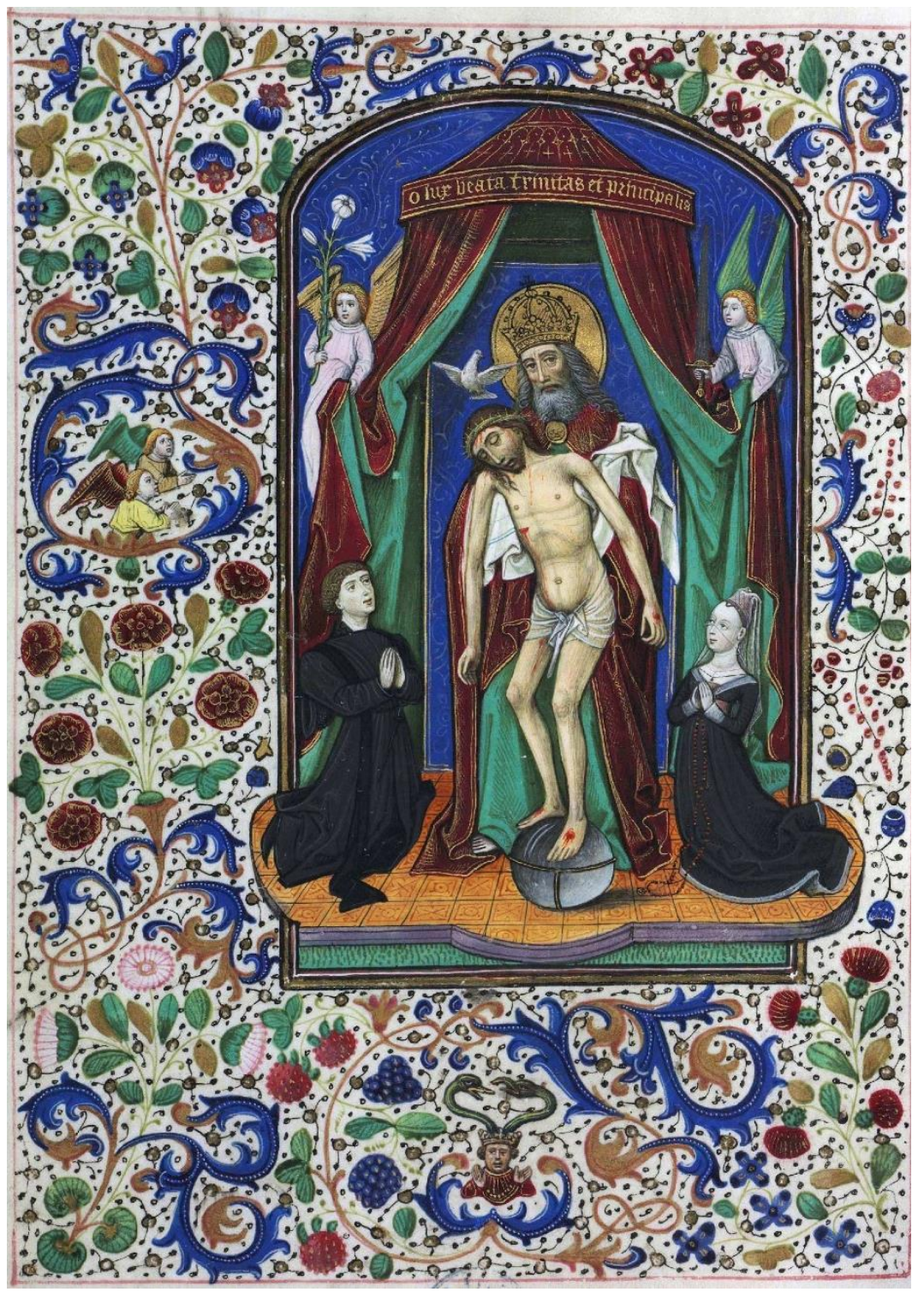

Fig. 4. Willem Vrelant, Trinidad. Libro de Horas de Leonor de la Vega. Siglo XV. Madrid @ Biblioteca Nacional (Vitr/24/2).

don Diego la carta de hidalguía por parte de Doña Juana como pago por los servicios prestados, por lo que en estas fechas no contaría con unas armas que le identificasen. Además, el calendario que figura en el Libro de Horas de Leonor de la Vega coincide con el de Brujas. Ello puede sostener las hipótesis de Juana Hidalgo ${ }^{39}$, quien afirmaba que nuestro ejemplar fuera una obra de taller realizada para venderla al primer cliente que se prestase a ello.

Por otro lado, la miniatura que ilustra el tema de la Trinidad, presenta en la escena a unos jóvenes personajes flanqueando a las figuras de Dios Padre y Cristo (Fig. 4). Su reducida escala con respecto a estas y su posición orante, respetuosa hacia el misterio de la Trinidad, así como sus elegantes y lujosos atavíos, a la moda flamenca, nos llevan a concluir que se trata de la representación de los donantes a los que iría dirigida la obra. Sobre sus

${ }^{39}$ Hidalgo, Libro de Horas de Leonor, p. 148. 
identidades, la ausencia de atributos representativos o armas familiares, nos impiden alcanzar alguna conclusión ${ }^{40}$. Por lo tanto, tan solo podemos apuntar que se pudo tratar de un encargo anterior, o que se incluyeron esas figuras estandarizadas y genéricas para poder ser vendido como regalo de compromiso.

A estos hechos debemos sumar que el estilo de las miniaturas, si bien se asemeja formalmente en sus rasgos principales al de las figuras de Vrelant en otros trabajos documentados, en este caso no coinciden totalmente y encontramos ligeras variaciones que podrían ser interpretadas como fruto de un trabajo colaborativo de taller.

El Libro pasó a manos de Doña Leonor de la Vega, hija de García Laso de la Vega, quien, tras casarse con Don Luis Portocarrero, Conde de Palma, fue a vivir a Jaén, de ahí que aparezca el nombre de esa ciudad bajo el nombre de la propietaria.

La tercera y última pista que nos ofrece el manuscrito procede de la inscripción inquisitorial, fechada en 1574. Por estas fechas la presión de la Inquisición imbuida por el espíritu de la Contrarreforma era bastante acusada, sobre todo en cuanto a publicaciones religiosas se refiere. Diego Ramírez, a consecuencia de su relación clientelar con Hernando de Talavera, abogaba por una devotio moderna, corriente afín a prácticas religiosas más personales donde imperaba la fe sobre el resto de las cuestiones. Esto le llevó a granjearse importantes enemigos dentro de las altas esferas religiosas, igual que le sucedió a su valedor. Del mismo modo que su pertenencia a la casa de Talavera le instaló en el primer plano político, también le apartó del mismo una vez hubo fallecido el patrón.

Hemos comprobado anteriormente cómo en esta época, la relación entre ambos clérigos era más que fluida, por lo que sus respectivas inclinaciones religiosas no debían andar muy distantes. Uno de los gustos de esta corriente religiosa era la predilección por la temática cristológica, más cargada de sentimiento y emociones. La práctica de este tipo de devoción llevó, quizás, a enviar Villaescusa precisamente este Libro de Horas a Garcí Laso, quien también debía sentir debilidad por esta corriente, pues aparte de las habituales Horas de la Cruz, encontramos diferentes oraciones a Cristo, situación poco habitual en el esquema típico de libro de horas. A pesar de ello los inspectores dieron el visto bueno, por lo que no debió levantar sospechas a los inquisidores.

\footnotetext{
40 Se puede establecer cierto paralelismo en cuanto a indumentaria, peinados, tocados y posturas, con las figuras de donantes que representaban algunos maestros de la segunda mitad del siglo XV, especialmente al círculo de Hugo van der Goes en su Calvario, recientemente adquirido para el Museo del Prado. Ángel Rodríguez, "Un Calvario del círculo de van der Goes para el Prado", Ars Magazine. Revista de Arte y Coleccionismo, 2 de diciembre, (2020), (En web: https://arsmagazine.com/un-calvario-del-circulo-devan-der-goes-para-el-prado/, consultada: 2 de diciembre de 2020).
} 


\section{Tapiz de la Crucifixión y otras noticias}

En 1502 Villaescusa volvió definitivamente de Flandes acompañando a los archiduques Felipe y Juana, que iban a ser jurados herederos al trono de Castilla en Toledo y de Aragón en Zaragoza. En la capital castellana volvió a coincidir con la reina Isabel la Católica, con quien, ya en la recta final de su vida, pareció volver a congraciarse el obispo de Málaga. Éste, en muestra de su gratitud por las mercedes recibidas, había encargado ex profeso un paño para la reina que fue recogido en los inventarios posteriores de la Casa Real ${ }^{41}$. El coleccionismo de tapices era considerado en su época como una de las más extendidas manifestaciones de lujo y riqueza entre las elites sociales, por su valor económico, emblemático, artístico y social. Debemos tener en cuenta, asimismo, la existencia de un hábito social, muy extendido desde finales de la Edad Media, por el que se reconocía la liberalidad y generosidad junto al resto de valores, como el honor o la honra, que debía atesorar una persona perteneciente a la nobleza ${ }^{42}$. En este contexto, el regalo de textiles en general, y tapices, en particular, se convertía en una costumbre social que elevaba la nobleza del donante y agasajaba al receptor.

La pieza terminó desapareciendo, o al menos lo hizo su rastro, al igual que otras muchas obras de similar factura. La gran problemática de la conservación de tapices estribaba en la dualidad de sus funciones que los convertían al mismo tiempo piezas de lujo y en objetos utilitarios. Por una parte, eran considerados en su tiempo una obra artística de primera fila y se adornada con ricos hilos de oro y plata, "la última y fastuosa, a la vez que práctica, moda de ultrapuertos"43. Por otro lado, eran considerados también un elemento del ajuar doméstico cortesano, siendo mostrados por los anfitriones a las visitas junto a las vajillas de metales preciosos, como parte de sus tesoros ${ }^{44}$. Como tal, se veían sometidos a múltiples mudanzas y maltratos, con el deterioro que conlleva en un material tan delicado. A resultas de estas condiciones, son pocos los tapices que se conservan de esta época de corte itinerante. Aun así, podemos hacernos una ligera idea sobre su aspecto gracias a la descripción que transcribió Sánchez Cantón en su citada obra:

\footnotetext{
"Rescebistes en la cibdad de Toledo a veynte e quatro días del mes de mayo de mill e quinientos e dos años un paño de Ras de devoción rico de oro e plata e seda e lana ques un crucifijo puesto en la cruz y los ladrones y la Madalena abraçada al pié de la Cruz y nuestra Señora y San Juan y las otras Marías con otra gente
}

\footnotetext{
${ }^{41}$ En este caso la obra no habría sido realizada para su venta a cualquier cliente, sino que sus destinatarios eran los monarcas hispanos, como demuestra el hecho de que aparecieran representadas las armas de los Reyes Católicos en la parte baja de la composición.

42 Andrés Sila Oreja, "El obsequio de tejidos como gesto de munificencia en el tardomedievo castellano: testimonios literarios", Anales de historia del arte, 24, (2014), pp. 389-400.

43 Francisco Javier Sánchez Cantón, Libros, tapices y cuadros que coleccionó Isabel la Católica, (Madrid: CSIC, 1950), p. 92

44 Miguel Ángel Zalama Rodríguez, Juana I. Arte, poder y cultura en torno a una reina que no gobernó, (Madrid: Centro de Estudios Europa Hispánica, 2010), pp. 55-56.
} 
armada a caballo e a pie, que tiene las orillas labradas de unos follajes verdes y azules con mucho oro, y los Profetas con unos rótulos en las manos y en lo baxo un escudo de las armas Reales, que tiene de largo dos varas e tres quartas e de caída tres varas e media de largas; el qual dio en servicio a Su Alteza el obispo de Málaga don diego Ramírez mi capellán mayor"45.

Diego Ramírez trajo consigo el tapiz como regalo a la reina desde Bruselas, donde había permanecido los últimos años al frente de la Casa de Juana y llevando a cabo diversos encargos diplomáticos para los monarcas. Bruselas era entonces el centro neurálgico de la manufactura de estas joyas decorativas, contando con los talleres más importantes del momento ${ }^{46}$; además de poseer una mano de obra cualificada, allí se concentraban desde finales del siglo XV los más destacados pintores flamencos, quienes aportaban en sus tablas originales modelos de calidad preparados para ser pasados a tapiz, como pueden suponer los casos de Memling, David, Metsys, Gossaert o Isenbrandt entre otros ${ }^{47}$.

Precisamente, entre los cortesanos de Felipe el Hermoso, encontramos a uno de los más importantes diseñadores de tapices del momento, como era Pieter van Aelst. El artista había sido nombrado ayudante de cámara y tapicero en la Casa del archiduque en el mismo año de $1502^{48}$. En calidad de miembro de su Casa viajó a la península ibérica junto a sus señores, desplazándose a Toledo para conservar y aderezar los paños que portaban, además de atender los encargos que se le ofrecieran. Sin embargo, el artista no trabajaba exclusivamente para la Casa de Felipe, ya que se han documentado numerosos trabajos realizados para Juana, como una venta que realizó a Juana de una serie de seis tapices «de la devoción de Nuestra Señora"49.

El hecho de que el artista hubiera trabajado para Juana nos invita a suponer que Villaescusa pudiera haber entrado en contacto con él. Asimismo, se trataba de un obsequio de gratitud a la reina más poderosa de Europa por las mercedes recibidas, que no eran pocas ni exiguas, por lo que cabe imaginar que no especularía con el encargo e invertiría una gran cantidad de dinero en él. En este sentido, hemos visto cómo la descripción de la pieza mostraba la riqueza artística y material que lo corroboraría. Al mismo tiempo, resultaría

\footnotetext{
45 AGS, CMC, $1^{\text {a }}$ época. leg. 186. Libro de cuentas del Camarero Sancho Paredes año 1505 en adelante. Sánchez Cantón, Libros, tapices y cuadros, p. 121.

${ }^{46}$ Desde finales del siglo XV hasta bien entrado el siglo XVI Bruselas dominaría la manufactura de telas ricas europea con talleres tan importantes como los de Pierre van Aelst o Guillaume de Pannemaeker. Sophie Schneebalg-Perelman, Alain Erlande-Brandenburg, La tapisserie des Pays-Bas sous les ducs de Bourgogne, (Bruxelles: Archives et bibliothèques de Belgique, 2003).

47 Elsje Janssen, "Le costume dans la tapisserie bruxelloise de la fin du XV et du debut du XVI siecle", en Âge d'or bruxellois. Tapisseries de la couronne d'Espagne, (Bruxelles: Editions de la Lettre Volée, 2000), p. 131.

48 Concha Herrero Carretero, "La Colección de Tapices de la Corona de España. Notas sobre su formación y conservación", Arbor, CLXIX, 665, (2001), pp. 163-192.

${ }^{49}$ Aunque el pago de los tapices se hizo ya en Toledo en 1502, se cree que pudieron ser encargados hasta seis años antes, con motivo de las bodas de los archiduques. Zalama, Juana I. Arte, poder, p. 308.
} 
incoherente pensar que, teniendo a mano el mejor taller de Brabante, Villaescusa decidiera comisionar la obra a cualquier otro. Podemos especular, por tanto, con que el obispo de Málaga recurriese a Pieter van Aelst para la ejecución del encargo.

Un último detalle nos indica el valor que pudo tener la obra, así como la consideración que se le tuvo desde el primer momento. El obsequio del conquense tuvo que ser muy apreciado por parte de la reina, pues ha quedado constancia de que el 25 de agosto del mismo mes, en Toledo, se encargó un cajón para guardarlo durante los constantes traslados junto a otros importantes tapices regalados por el rey y otras personalidades ${ }^{50}$.

Además de este valioso presente a la reina, se sabe que Villaescusa, en algún momento anterior a 1504, regaló a sus majestades dos pinturas religiosas: "Otras dos tablas - uno es un retablico de tres piezas que dio madama de Luy y el otro son dos tablas de N. Señor y N. Señora que dio el obispo de Malaga a sus altezas" 51.

Dichas pinturas debieron ser traídas desde Flandes en el mismo viaje que el citado tapiz, aunque la falta de documentos que lo confirmen hace que no podamos pronunciarnos abiertamente en cuanto a su datación y autoría; pero si tenemos en cuenta la importante suma que debió gastar en el encargo del tapiz y la búsqueda del favor real es lógico pensar que para este encargo buscó una obra de calidad. Por ello, es posible que las tablas -seguramente un díptico, ya que se mencionan como una sola unidad- fueran de una calidad más que aceptable, debiendo pertenecer a algún importante taller flamenco. Villaescusa, no obstante, pudo encargar las tablas, o bien tuvo que acudir a algún intermediario para que las comprase en el mercado libre, como era habitual entre los consumidores extranjeros de arte flamenco ${ }^{52}$.

Al carecer de descripción alguna y, dado que más allá de los protagonistas de la obra no contamos con más información, no podemos establecer con seguridad ninguna hipótesis sobre su procedencia o autoría, ni siquiera sobre su iconografía. Sin embargo debemos tener en cuenta algunos factores que pueden acercarnos al tipo de conjunto que regaló Villaescusa a la reina: si las obras fueron traídas desde Flandes en el viaje que hizo el capellán de la archiduquesa, sus dimensiones debían ser más bien reducidas, una pieza fácilmente transportable dado lo trabajoso de su traslado; el hecho de que se mencione en el mismo asiento que el "retablico" de madama de Luy, nos indica que ambos conjuntos debían responder a una tipología similar; debió

\footnotetext{
${ }^{50}$ Amalia Prieto Cantero, Casa y descargo de los Reyes Católicos, (Valladolid: Instituto Isabel la Católica de Historia Eclesiástica, 1969), p. 74.

${ }^{51}$ Libro de Juan Velazquez de las cosas que reçibió de la Camara de la Reyna, AGS. CMC, $1^{\text {a }}$ época, leg. 189, fol. 1, en Sánchez Cantón, Libros, tapices y cuadros, p. 169.

52 Pilar Silva Maroto, "Los primitivos flamencos en España. Un boceto de la introducción en España en el siglo XV del arte, los artistas y los estilos flamencos", conferencia impartida en el Congreso de los Austrias españoles y los Países Bajos, (19), 20-21 de marzo de 2000, Amberes. (En web: https://www.codart.nl/our-events/codart-drie/codart-drie-congress/pilar-silva-codart-drie/, consultada: 17 de mayo de 2020).
} 


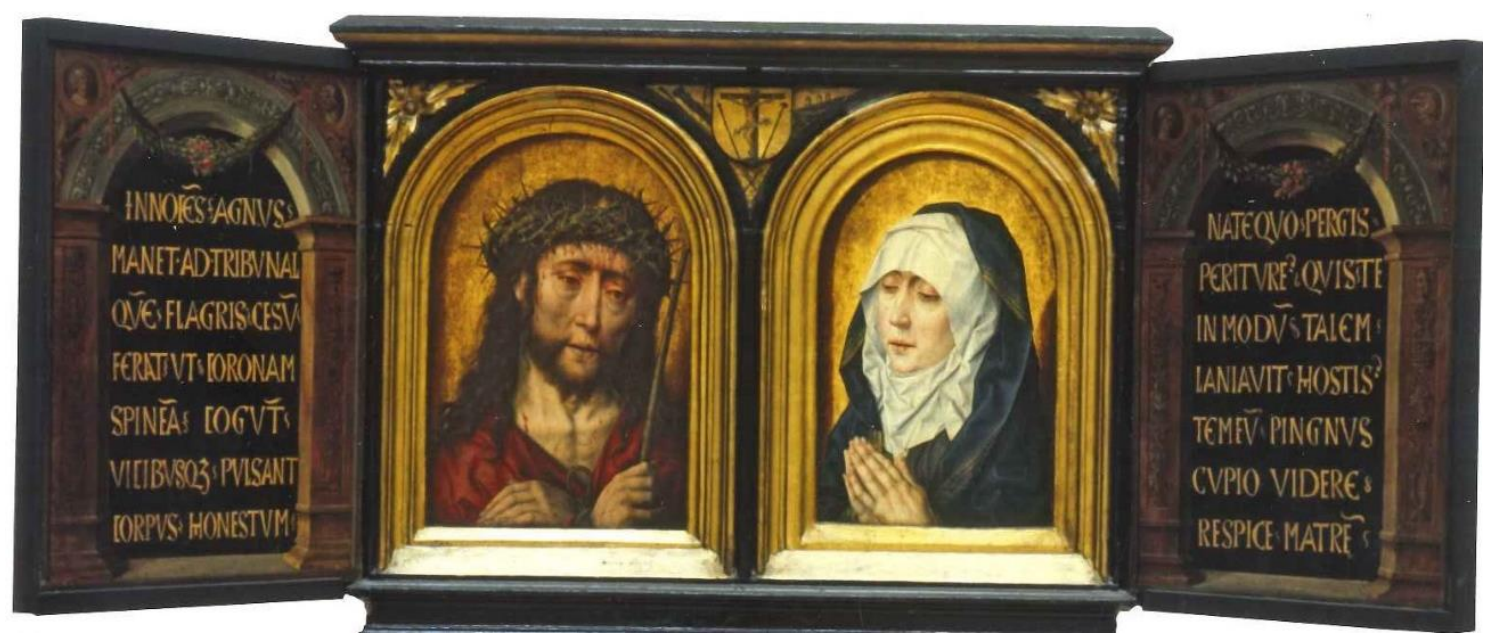

Fig. 5. Albrecht Bouts y taller, Díptico del Ecce Homo y la Dolorosa. Aquisgrán, @Museo Suermondt-Ludwig (inv./cat.nr GK 57).

de tratarse, por tanto, de un pequeño díptico de devoción, para la Capilla privada de la reina.

Es muy posible que las figuras representadas en las tablas fueran un Ecce Homo y una Dolorosa, aunque también podría tratarse de un Crucificado y una Quinta Angustia. Estos conjuntos iconográficos eran más que habituales en la producción de los talleres flamencos de la época y gozaban de relativo éxito. En este aspecto, debemos resaltar la popularización de ciertas composiciones de herencia "weydeniana", como las que Dirk Bouts y el taller que desarrollaron sus hijos en Lovaina (Fig. 5). En ellas se representaban el Ecce Homo y la Dolorosa, de busto o de medio cuerpo, con un marcado carácter devocional y de pequeñas dimensiones que facilitaban su transporte. Esta tipología de tablas estaba vinculada a la religiosidad intimista y personal que se asociaba a la ya mencionada devotio moderna ${ }^{53}$.

La reina contaba al final de su vida con algunos ejemplos de este tipo de dípticos, como ha quedado constatado en los registros de la almoneda de Toro, donde se vendieron los bienes de la Casa de Isabel"54: "Dos tablas, una de un Christo y la otra de nuestra Señora, medios cuerpos, de rroble de Flandes 8 ducados de oro. Vendiose a M. de Fonseca en 3.000 maravedíes" $^{\prime 55}$.

\footnotetext{
53 Véase el díptico con esta temática atribuido a Albrecht Bouts y conservado en Aquisgrán, Museo Suermondt-Ludwig. Ernst Günther Grimme, Führer durch das Suermondt-Museum Aachen: Skulpturen, Gemälde, Schatzkunst, (Aachen: Verlag des Museumvereins Aachen, 1974). Al autor se le dedicó recientemente una exposición y la publicación de su correspondiente catálogo, donde se trata precisamente de esta pieza. V. Hendericks, "Albrecht Bouts und Werstatt. Ecce Homo, Mater Dolorosa, Verkündigung (Flügel)", en Blut und Tränen. Albrecht Bouts un das Antlitz der passion, ed. Valentine Henderiks, (Regensburg: Schell \& Steiner, 2016), pp. 112-115. Se puede acceder a una reseña de la exposición en Miquel Herrero-Cortell, "Exposición: 'Blut und Tränen. Albrecht Bouts und das Antlitz der pasion' Musée National d'Histoire et d 'Art Luxembourg y Surmondt-Ludwig-Museum de Aquisgrán, 2017", Philostrato. Revista de Historia y Arte, no 2, 2017, pp.85-87.

54 Encontramos varios registros que contienen dípticos en los que se describen las citadas representaciones. Carmen Manso Porto, Isabel la Católica y el Arte, (Madrid: Real Academia de la Historia, Marquesa viuda de Arriluce de Ybarra, 2006), pp. 33 y ss.

${ }^{55}$ Ibídem, p. 38.
} 
La presencia de estas obras en la almoneda de la reina Isabel confirma la afición que, bien la propia reina o bien el comitente que le proporcionase aquellas piezas, tenían por dicho género de pinturas. Villaescusa, conocedor de las prácticas cortesanas y del gusto de los monarcas, les obsequiaba con obras suntuosas como el tapiz, buscando mostrar un agradecimiento económico, pero también manifestaba una gratitud personal, regalando unas tablas devocionales que se dirigían directamente a la devoción individual, privada e interior de la reina.

Una vez fallecida la reina Isabel, Villaescusa quiso aprovechar la referida almoneda celebrada en Toro para hacerse con algunas piezas pertenecientes a su difunta protectora, por lo que debió enviar a algún emisario para que se hiciera con las obras que le resultaran más interesantes. Ha quedado constancia de la adquisición por parte del obispo de Málaga, además de los anteriormente referidos libros de su colección, de uno de los tapices que había pertenecido a la Casa de la reina: "Que se vendió al obispo de Málaga un paño de Ras rico con oro en que está Nuestro Señor e la cruz entre dos ladrones y en lo alto Dios Padre y Adán y Eva y en lo baxo del Nascimiento de Nuestro Señor, en cient ducados de oro"56.

No hemos podido recabar información sobre cuál fue el destino de este tapiz, si lo llevó consigo a Málaga o a su capilla de Villaescusa de Haro, si lo utilizó para agasajar a otra persona o si se lo quedó para sí. No obstante, teniendo en cuenta que tenía previsto instalarse en su diócesis malacitana, lo más probable es que lo utilizase para vestir las paredes de sus palacios episcopales.

\section{Conclusión}

Estas intervenciones y adquisiciones artísticas nos presentan a Villaescusa como un patrón artístico que utilizaba las obras con un objeto social, devocional y utilitario. Ello le arrastraba a interesarse por este tipo de obras de arte sin importarle en absoluto el precio de las mismas, pues cien ducados de oro eran una cifra bastante elevada para un personaje en ascenso, pero aún alejado de las más altas dignidades. Quizás esta actitud sea muestra de que él mismo se veía equiparado, en poder e influencia, a las elites de la Monarquía y tratara de comportarse como uno de ellos ${ }^{57}$.

Gracias a su cercanía a la Corte, donde dominaba sin oposición el arte flamenco, se empapó del gusto de los monarcas, que se remitía a una tradición nórdica cuyo estilo fastuoso, narrativo y simbólico se adecuaba a la piedad y el mensaje de exaltación monárquica y religiosa. Con su viaje a los Países Bajos esta mentalidad enraizó en nuestro personaje, quien comenzó a encargar y adquirir diferentes obras del gusto oficial tanto para obsequiar a

56 Sánchez Cantón, Libros, tapices y cuadros, p. 148.

57 Tal estipendio solamente pudo darse gracias a la devolución de un préstamo que hizo a los reyes para la campaña del Rosellón. Había donado la cantidad de 100 marcos de plata, que le fueron devueltos en dineros, en diciembre de 1504, recibiendo la nada despreciable cantidad de 640 ducados. AGS, CSR, leg, 5 , fol. 19. 
los monarcas como para sí mismo. Se iniciaba así en Villaescusa una larga trayectoria como consumidor, protector y promotor de las artes, marcada por una permeabilidad que le llevaría a aceptar los estilos y formas dominantes en cada lugar y en cada momento. Sin embargo, a pesar de los cambios de gusto que manifestaría, sería una constante la búsqueda de la calidad y el lujo en cada una de sus intervenciones, mostrándose como un espléndido mecenas. 
Bibliografía:

Angulo 1980: Diego Angulo Íñiguez, Historia del Arte, Tomo I, (Madrid: Raycar, 1980).

Bousmanne 1997: Bernard Bousmanne, "Item a Guillaume Wywelant aussi eluminieur", en Willem Vrelant. Un aspect de 'lenluminure dans les Pays-Bas meridionaux sous le mécenat de ducs de Bourgogne Philippe le Bon el Charles le Témeraire, (Bruxelles: Bibliotheque Royal de Belgique,1997).

Delaissé 1974: Leon M. J. Delaissé, "The importance of Books of Hours for the History of the Medieval Book", en Gatherings in honor of Dorothy E. Miner, eds. Dorothy Eugenia Miner, Ursula E. McCracken, Lilian M. C. Randall, Richard H. Randall, (Baltimore: Walters Art Gallery, 1974), pp. 203-225.

Dijk 2014: Mathilde van Dijk, "The Devotio Moderna, the Emotions and the Search for 'Dutchness'", en Low Countries Historical Review, 129-2, (2014), pp. 20-41.

Domínguez Rodríguez 2000: Ana Domínguez Rodríguez, "Libros de Horas en la Corona de Castilla. Hacia un estado de la cuestión", Anales de Historia del Arte, 10, (2000), pp. 9-54.

Domínguez Rodríguez 1979: Ana Domínguez Rodríguez, Libros de Horas del siglo XV en la Biblioteca Nacional, (Madrid: Fundación Universitaria Española, 1979).

Durrieu 1983: Paul Durrieu, "Manuscrits d'Espagne remarcables par leur peinture et par la beauté de leur execution", Bibliothèque de l'Ecole de Chartres, 54, (1983).

Fagel 2006: Raymond Fagel, "Juana de Castilla y los Países Bajos: la Historiografía neerlandesa sobre la reina", en Juana I de Castilla, 1504-1555: de su reclusión de Tordesillas al olvido de la historia: I Simposio Internacional sobre la Reina Juana I de Castilla, coord. Miguel Ángel Zalama Rodríguez, (Tordesillas [Valladolid]: Ayuntamiento de Tordesillas, 2006), pp. 87-706.

Gombrich 1992: Ernst H. Gombrich, Historia del Arte, (Madrid: Alianza Forma, 1992).

González Dávila 1606: Gil González Dávila, Historia de las Antigüedades de la ciudad de Salamanca, (Salamanca, 1606). Publicado por Baltasar Cuart Moner en Salamanca, (Salamanca: Ediciones Universidad de Salamanca, 1994)

González Romero 2016: José Fernando González Romero, El gótico alemán en España y la dinastía de los Colonia. La cristalización de las torres caladas: Friburgo, Burgos y Oviedo, (Gijón: Ediciones Trea, 2016)

Grimme 1974: Ernst Günther Grimme, Führer durch das Suermondt-Museum Aachen: Skulpturen, Gemälde, Schatzkunst, (Aachen: Verlag des Museumvereins Aachen, 1974). 
Hendericks 2016: V. Hendericks, "Albrecht Bouts und Werstatt. Ecce Homo, Mater Dolorosa, Verkündigung (Flügel)", en Blut und Tränen. Albrecht Bouts un das Antlitz der passion, ed. Valentine Henderiks, (Regensburg: Schell \& Steiner, 2016), pp. 112-115.

Herrero Carretero 2001: Concha Herrero Carretero, "La Colección de Tapices de la Corona de España. Notas sobre su formación y conservación", Arbor, CLXIX, 665, (2001), pp. 163-192.

Herrero-Cortell 2017: Miquel Herrero-Cortell, "Exposición: 'Blut und Tränen. Albrecht Bouts und das Antlitz der pasion' Musée National d'Histoire et d'Art Luxembourg y Surmondt-Ludwig-Museum de Aquisgrán, 2017" en Philostrato. Revista de Historia y Arte, no 2, 2017, pp.85-87.

Hidalgo Ogáyar 2000: Juana Hidalgo Ogáyar, Libro de Horas de Leonor de la Vega, (Madrid: Versol, 2000).

Janssen 2000: Elsje Janssen, "Le costume dans la tapisserie bruxelloise de la fin du XV et du debut du XVI siecle", en Âge d'or bruxellois. Tapisseries de la couronne d'Espagne, (Bruxelles: Editions de la Lettre Volée, 2000).

Jonge 2005: Krista de Jonge, "Flandes y Castilla. La arquitectura en la época de los Reyes Católicos" en El arte en la Corte de los Reyes Católicos. Rutas artísticas a principios de la Edad Moderna, eds. Fernando Checa Cremades y Bernardo J. García García, (Madrid: Fundación Carlos de Amberes, 2005), pp. 167-182.

Knighton 2017: Tess Knighton, Companion to Music in the Age of the Catholic Monarchs, (Leiden: Brill, 2017).

Kren, McKendrick 2003: Iluminating the Renaissance: The Triumph of Flemish Manuscript Painting in Europe, ed. Thomas Kren y Scot McKendrick, (Los Ángeles: Paul Getty Museum; Londres: Royal Academy of Arts, 2003).

Labrador Arroyo 2018: Félix Labrador Arroyo, "La evolución y el papel de las casas reales en Castilla entre 1504 y 1516", en Poder, sociedad, religión y tolerancia en el mundo hispánico, de Fernando el Católico al siglo XVIII, eds. Eliseo Serrano Martín, Jesús Gascón Pérez, (Zaragoza: Institución Fernando el Católico, Excma. Diputación de Zaragoza, 2018), pp. 119-155.

Leroquais 1927: Victor Leroquais, Les libres d'heures manuscrits de la Bibliothèque Nationale, (París: Maçon Protat frères, 1927), 3 vols.

López 1949-1953: Mateo López, Memorias históricas de Cuenca y su obispado, (Cuenca: Instituto Jerónimo Zurita del Consejo Superior de Investigaciones Científicas, 1949-1953).

Manso Porto 2006: Carmen Manso Porto, Isabel la Católica y el Arte, (Madrid: Real Academia de la Historia, Marquesa viuda de Arriluce de Ybarra, 2006).

Nogales Rincón 2014: David Nogales Rincón, "Sobre la cultura "borgoñona" y su recepción en Castilla en el siglo XV", en La Casa de Borgoña. La Casa del 
rey de España, eds. José Eloy Hortal Muñoz y Félix Labrador Arroyo, (Leuven: Leuven University Press, 2014), pp. 23-35.

Ochoa Brun 1995: Miguel Ángel Ochoa Brun, Historia de la diplomacia española, vol. IV, (Madrid: Ministerio de Asuntos Exteriores, 1995).

Olmedo 1944: Félix G. Olmedo, Diego Ramírez Villaescusa (1459-1537), fundador del Colegio de Cuenca y autor de los cuatro diálogos sobre la muerte del Príncipe Don Juan, (Madrid: Editora Nacional, 1944).

Panofsky 1998: Erwin Panofsky, Los primitivos flamencos, (Madrid: Cátedra, 1998, 2016).

Prieto Cantero 1969: Amalia Prieto Cantero, Casa y descargo de los Reyes Católicos, (Valladolid: Instituto Isabel la Católica de Historia Eclesiástica, 1969).

Sáez Olivares 2020: Alejandro Sáez Olivares, El obispo Diego Ramírez de Villaescusa y su papel como mecenas de las artes, tesis doctoral. Universidad Rey Juan Carlos, (Madrid: 2020).

Sánchez Cantón 1950: Francisco Javier Sánchez Cantón, Libros, tapices y cuadros que coleccionó Isabel la Católica, (Madrid: CSIC, 1950).

Schneebalg-Perelman y Erlande-Brandenburg 2003: Sophie SchneebalgPerelman, Alain Erlande-Brandenburg, La tapisserie des Pays-Bas sous les ducs de Bourgogne, (Bruxelles: Archives et bibliothèques de Belgique, 2003).

Sila Oreja 2014: Andrés Sila Oreja, "El obsequio de tejidos como gesto de munificencia en el tardomedievo castellano: testimonios literarios", en Anales de historia del arte, 24, (2014), pp. 389-400.

Silva Maroto 2000: Pilar Silva Maroto, "Los primitivos flamencos en España. Un boceto de la introducción en España en el siglo XV del arte, los artistas y los estilos flamencos", conferencia impartida en el Congreso de los Austrias españoles y los Países Bajos, (19), 20-21 de marzo de 2000, Amberes. (En web: https://www.codart.nl/our-events/codart-drie/codart-drie-congress/pilar-silvacodart-drie/, consultada: 17 de mayo de 2020).

Silva Maroto 2003: María Pilar Silva Maroto, "La pintura hispanoflamenca en Castilla" en La pintura gótica hispanoflamenca: Bartolomé Bermejo y su época, ed. Francesc Ruiz Quesada, (Barcelona: Museu Nacional d'Art de Catalunya, Museo de Bellas Artes de Bilbao, 2003), pp. 77-86.

Vázquez Dueñas 2016: Elena Vázquez Dueñas, Felipe de Guevara. Comentario de la pintura y pintores antiguos, (Madrid: Akal, 2016).

Wieck 1997: Roger S. Wieck, Painted prayers: the book of hours in medieval and Renaissance art, (New York: George Braziller, in association with the Pierpont Morgan Library, 1997).

Yarza Luaces 1992: Joaquín Yarza Luaces, "El arte de los países bajos en la España de los Reyes Católicos" en Reyes y mecenas. Los Reyes Católicos, 
Maximiliano I y los inicios de la Casa de Austria en España, coord. Fernando Checa, (Madrid: Electa, 1992), pp. 134-135.

Yarza Luaces 1993: Joaquín Yarza Luaces, Los Reyes Católicos. Paisaje artístico de una monarquía, (Madrid: Editorial Nerea, 1993).

Zalama Rodríguez 2008: Miguel Ángel Zalama Rodríguez, "La infructuosa venta en almoneda de las pinturas de Isabel la Católica" en BSAA Arte, no 74, (2008), pp. 45-66.

Zalama Rodríguez 2010: Miguel Ángel Zalama Rodríguez, Juana I. Arte, poder y cultura en torno a una reina que no gobernó, (Madrid: Centro de Estudios Europa Hispánica, 2010).

Zalama Rodríguez 2011: Miguel Ángel Zalama Rodríguez, "Primacía de los tapices entre las artes figurativas en España entre los siglos XV y XVI" en Los triunfos de Aracne. Tapices flamencos de los Austrias en el Renacimiento, eds. Fernando Checa Cremades y Bernardo J. García García, (Madrid: Fundación Carlos de Amberes, 2011), pp. 17-38.

Recibido: 7/12/2020

Aceptado: $28 / 04 / 2021$ 